Canadian Journal of Fisheries and Aquatic Sciences

Canadian Science Publishing

Journal canadien des sciences halieutiques et aquatiques

\title{
Spatio-temporal index standardization improves the stock assessment of northern shrimp in the Gulf of Maine
}

\begin{tabular}{|r|l|}
\hline Journal: & Canadian Journal of Fisheries and Aquatic Sciences \\
\hline Manuscript ID & cjfas-2016-0137.R4 \\
\hline Manuscript Type: & Article \\
\hline Date Submitted by the Author: & 22-Feb-2017 \\
\hline Complete List of Authors: & $\begin{array}{l}\text { Cao, Jie; University of Maine, school of marine sciences } \\
\text { Thorson, James T.; Northwest Fisheries Science Center, National Marine } \\
\text { Fisheries Service, NOAA } \\
\text { Richards, R. Anne; Northeast Fisheries Science Center, National Marine } \\
\text { Fisheries Service } \\
\text { Chen, Yong; University of Maine, }\end{array}$ \\
\hline Keyword: & $\begin{array}{l}\text { abundance index, delta-generalized linear mixed model, Gaussian random } \\
\text { field, spatial modeling, size-structured assessment model }\end{array}$ \\
\hline &
\end{tabular}


3 Spatio-temporal index standardization improves the stock assessment of northern shrimp in the Gulf of Maine

\section{5}

6

$12{ }^{2}$ Fisheries Resource Assessment and Monitoring Division, Northwest Fisheries Science Center, National Marine Fisheries Service, NOAA, Seattle, WA, USA

16 Correspondence Email: jie.cao@maine.edu 


\section{ABSTRACT}

Estimated trends in relative stock abundance are a primary input to fish stock assessments.

19 Accurate and precise estimates are essential for successful conservation and management.

20 Scientifically designed data collection ensures that estimates of relative abundance are unbiased.

21 However, the statistical efficiency of a design-based estimator may be low under certain

22 circumstances. We apply a recently developed spatio-temporal model that incorporates habitat

23 variables to estimate a model-based abundance index for northern shrimp (Pandalus borealis) in

24 the Gulf of Maine. We contrast this spatio-temporal index with a classical design-based index

25 and evaluate the impacts of differences between the two abundance indices on the stock

26 assessment. We show that using the spatio-temporal index in the assessment model greatly alters

27 the estimates of recruitment and spawning stock biomass and the determination of stock status.

28 Also, incorporating the spatio-temporal index leads to less retrospective bias and outperforms the

29 model with design-based index in terms of predictive performance through a retrospective cross-

30 validation test. Our results suggest that temporal variability of population abundance could be

31 exaggerated by the design-based estimator and such imprecision may greatly affect the

32 performance of a stock assessment and subsequent development of management decisions.

34 Keywords: abundance index, delta-generalized linear mixed model, Gaussian random field, 35 spatial modeling, size-structured assessment model 


\section{INTRODUCTION}

Periodic fishery independent surveys provide important information for fisheries stock assessment and management. Abundance indices are often the primary information derived from the surveys, and are essential to perform an adequate assessment. Contemporary assessments largely rely upon abundance indices which are assumed to be proportional to population

41 abundance (Maunder and Punt 2004). The precision of these estimates is critical in influencing

42 uncertainty associated with stock assessment and subsequent development of management

43 decisions (e.g., total allowable catches).

44 There are mainly two types of methods used to estimate abundance indices from fishery

45 independent surveys: classical design-based estimators and model-based estimators. Fishery

46 independent surveys are generally well designed statistically with randomized sampling locations.

47 They usually have stratified random design as appropriate stratification can increase the

48 precision of estimates with limited sampling effort (Cao et al. 2015). The design-based

49 estimators infer the population abundance according to the randomness induced by the sampling

50 design. For example, the commonly used stratified-random design estimator generates the

51 abundance index as the stratified mean for each stratum weighted by area (Smith 1990).

52 However, model-based approaches analyze the survey data conditional on a hypothesized

53 statistical model to control for confounding effects (e.g., differences in survey catchability;

54 Helser et al. 2004; Thorson and Ward 2014) and make inference according to an assumed

55 probability function for the response variable (Chen et al. 2004). These two different estimators

56 have different philosophies of statistical inference (Smith 1990). For design-based theory,

57 inferences about population quantities are based on assuming they are fixed, whereas application

58 of models assumes that there is an underlying stochastic process generating the data (Smith 
59 1990). Both design- and model-based estimators are commonly used in the United States (Helser

60 et al. 2004; Thorson et al. 2015).

61 Conventional models could produce biased estimates of abundance (Ye and Dennis 2009).

62 However, spatio-temporal models developed recently have been demonstrated to produce more

63 precise and accurate abundance indices than either design-based or conventional model-based

64 approaches (Shelton et al. 2014; Thorson et al. 2015). A spatio-temporal model can account for

65 spatial dependence which results in estimating a smoothed surface representing spatial variation

66 in density (Thorson et al. 2015). Also, habitat variables, e.g. (depth, bottom substrate type,

67 temperature and salinity), can be incorporated into the spatio-temporal model as covariates. This

68 can potentially lead to more precise estimates of abundance, especially when the underlying

69 population distribution is largely dependent on habitat variables. In contrast, conventional

70 design-based approaches cannot explicitly incorporate habitat variables and may produce

71 imprecise estimates of abundance, particularly in the situation where habitat preference occurs

72 and when strata included in the sampling design do not capture a large portion of spatial

73 variation in density. Shelton et al. (2014) showed that the habitat preference of darkblotched

74 rockfish in selected sampling locations can largely explain the variation in survey catch rates.

75 Therefore, the temporal variability of population abundance may be exaggerated by a design-

76 based estimator when the randomized sampling locations happen to fall in good habitat for some

77 years, and vice versa (Shelton et al. 2014).

78 The spatio-temporal model has been applied to data for 28 groundfish species off the U.S.

79 West Coast and the results were compared to a conventional model-based approach (Thorson et

80 al. 2015). In general, the spatio-temporal and stratified indices showed similar trends (Thorson et

81 al. 2015), while the uncertainty associated with the stratified index was substantially larger than 
82 that associated with the spatio-temporal index (Thorson et al. 2015). In some cases, a statistically

83 inefficient annual estimate from a design-based estimator (i.e., spikes in abundance index with

84 high expected imprecision) could be avoided by using a spatio-temporal model (Shelton et al.

85 2014). However, few studies have shown the impacts of disparity between spatio-temporal and

86 design-based indices on stock assessment results and performance. Given that the abundance

87 index provides primary information for stock assessment, such studies are needed to better

88 understand the practical importance of spatio-temporal index standardization.

89 We implement the spatio-temporal model to data collected from a summer shrimp bottom

90 trawl survey designed specifically for monitoring northern shrimp (Pandalus borealis) in the

91 western Gulf of Maine (GOM), and results are compared with an existing design-based index

92 used in the stock assessment. Habitat variables are included in the spatio-temporal model to

93 evaluate whether inclusion of habitat covariates helps explain the distribution of this species. We

94 then estimate parameters for a stock assessment model for northern shrimp using the spatio-

95 temporal index and compare the assessment model performance and outputs with those obtained

96 based on the design-based index. Northern shrimp serves as our case study for two reasons: (1)

97 there is high temporal variation observed in its design-based index, including an unlikely high

98 spike in 2006; and (2) northern shrimp are considered to be sensitive to environmental changes

99 (Richards et al. 2012) and there might be high inter-annual variation in their spatial distribution.

100 This paper presents a real fishery example to demonstrate that spatio-temporal index

101 standardization can improve the performance of a stock assessment model.

102

103 METHODS

104 Spatio-temporal delta generalized linear mixed model 
A zero-inflated generalized linear mixed modeling framework was used in this study.

106 This framework explains the catch (in numbers) as function of two processes: (1) the probability

107 of sampling habitat where the species is present; and (2) the distribution of catches in habitat

108 where the species is present. Sampling in unoccupied habitat will always generate a catch of

109 zero (a "true zero"), while sampling in occupied habitat may also generate a catch of zero (a

110 "false zero"; see Martin et al. (2005)). Specifically, catches were assumed to follow a zero-

111 inflated negative binomial distribution:

112

$$
\operatorname{Pr}[C=c \mid C>0]=\left\{\begin{array}{cc}
(1-p)+p \times \mathrm{NB}(C \mid n, r) & \text { if } C=0 \\
p \times \operatorname{NB}(C \mid n, r) & \text { if } C>0
\end{array}\right.
$$

113 where $p$ is the probability of sampling in where the species is present (so $1-p$ is the probability

114 of a "true" zero), and $\mathrm{NB}(c \mid n, r)$ is the negative binomial probability density function evaluated

115 at value $c$ with size $n$ and probability $r$. We specified a quadratic function for the variance of the

116 negative binomial distribution as a function of the mean:

$$
\sigma^{2}=\left(1+\theta_{1}\right) \lambda+\theta_{2} \lambda^{2}
$$

118 where $\lambda$ is the expected catch in occupied habitat, and where this variance was then used to

119 calculate the size and probability parameters $(r$ and $p$ ) for the negative binomial distribution:

$$
\begin{aligned}
& r=\lambda / \sigma^{2} \\
& n=\lambda r /(1-r)
\end{aligned}
$$

122 This distribution involves estimating the probability of sampling occupied habitat $(p)$, the

123 expected catch in occupied habitat $(\lambda)$, and two variance parameters $\left(\theta_{1}\right.$ and $\left.\theta_{2}\right)$, and its

124 expectation is then easily calculated $(\mathbb{E}(C)=p \times \lambda)$.

125 We accounted for spatial dependence in both the probability of occupied habitat $(p)$ and

126 the density given occupied habitat $(\lambda)$. Accounting for spatial dependence can lead to better

127 inference, superior prediction, and a more accurate characterization of the variability of estimates, 
128 and we did so in this model using Gaussian Markov random fields. Random fields describe

129 random processes defined over parameter spaces with multiple dimensions. For example, in

130 fisheries science the spatial parameter might represent variation in population density over two

131 dimensions (latitude and longitude). Specifically, spatial dependence can be imposed by

132 modeling a zero-mean stationary Gaussian random field, which defines the expected value,

133 variance, and covariance of a multivariate realization from a stochastic process. For a zero mean

134 stationary Gaussian random field $\mathrm{w}$, the value of $\mathrm{w}$ at a given location $\mathrm{s}=(\mathrm{x}, \mathrm{y})$ (where $\mathrm{x}$ and $\mathrm{y}$

135 are the easting and northing for that location) follows a normal distribution and the value of w at

136 a finite number of locations follows a multivariate normal distribution:

$$
\mathrm{w}[s] \sim M N\left(0, \sum \Theta\right)
$$

138 where $M N$ is a multivariate normal distribution, and $\sum \Theta$ is the covariance matrix of the two

139 dimensional normal density. We specified that the covariance follows a Matern function (with

140 smoothness $v=1$ ), which measures spatial proximity in terms of distances between the locations.

141 The Matern function is slightly more smooth than the exponential correlation function used in

142 other recent spatio-temporal models in fisheries science (e.g., Kristensen et al. 2014). While we

143 assumed that the random field is stationary, we included the potential impact of geometric

144 anisotropy in order to deal with the situation that dependence may be different in different

145 directions:

$$
\sum\left(s, s^{\prime}\right)=\sigma_{E}^{2} \cdot \operatorname{Matern}\left(\left\|\mathrm{H}\left(s-s^{\prime}\right)\right\|\right)
$$

147 where $\mathrm{H}$ is a linear transformation representing geometric anisotropy and can be derived from 148 two parameters (see Thorson et al. 2015, Appendix A for details), $s-s^{\prime}$ is the difference in 149 eastings and northings between locations $s$ and $s^{\prime}$, and $\left\|\mathrm{H}\left(s-s^{\prime}\right)\right\|$ is the distance between 
150 locations after accounting for geometric anisotropy (see Cressie and Wikle 2011, Eq. 4.9 for 151 details).

152 A piecewise constant approximation, which consists of reducing a random field w

153 defined over a spatial domain $\Omega$ to a set of knots, was used to approximate the random field w

154 (Thorson et al. 2015). To accomplish this, a desired number of knots $n_{j}$ need to be pre-specified.

155 Each knot is associated with a constant value of $\mathrm{w}$ and covariates, and the value of $\mathrm{w}$ at a given

156 location $s_{i}$ is determined from the value $\mathrm{w}$ at the knot that is nearest to $s_{i}$. A $k$-means algorithm

157 was applied to the location of survey data to determine the locations of all knots. The derived

158 distribution of knots reflects the sampling intensity of survey locations and stays the same among

159 years. The area $a_{j}$ of each knot $j$ was then calculated using the Voronoi tool in the PBSmapping

160 package in $\mathrm{R}$ (Schnute et al. 2013). The number of pre-specified knots is a compromise between

161 accuracy of the piecewise constant approximation and computational speed, and we confirmed

162 that all results are invariant to small increases in the number of knots used.

163 The probability of occupied habitat was modeled as a combination of linear predictors

164 (including random fields):

165

$$
p_{i}=\operatorname{logit}^{-1}\left(d_{T_{(i)}}^{(p)}+\sum_{k=1}^{n_{x}} \beta_{k}^{(p)} x_{J_{(i), k}}+\omega_{J_{(i)}}^{(p)}+\varepsilon_{J_{(i)}, T_{(i)}}^{(p)}\right)
$$

166 where $p_{i}$ is the probability of occupied habitat for sample $i$ at location $s_{i}, d_{T_{(i)}}$ is the average

167 density in year $t, \beta_{k}$ is the coefficient of covariate $x_{k}, J_{i}$ is the nearest knot to sample $i, \omega_{i}$ is the

168 value of random field at knot $j$ that is persistent among years, $\varepsilon_{j, t}$ is the value of random field at

$169 \operatorname{knot} j$ in year $t$, and $n_{x}$ is the number of covariates that are included in the model. The two

170 random fields were specified as:

171

$$
\omega^{(p)} \sim M N\left(0, \Sigma_{\omega}^{(p)}\right)
$$




$$
\varepsilon_{t}^{(p)} \sim M N\left(0, \Sigma_{\varepsilon_{t}}^{(p)}\right)
$$

173 Similarly, the expected positive catches $\lambda$ given occupied habitat for sample $i$ (i.e., the second

174 model component) was specified as:

$$
\lambda_{i}=w_{i} \exp \left(d_{T_{(i)}}^{(\lambda)}+\sum_{k=1}^{n_{x}} \beta_{k}^{(\lambda)} x_{J_{(i), k}}+\omega_{J_{(i)}}^{(\lambda)}+\varepsilon_{J_{(i)}, T_{(i)}}^{(\lambda)}\right)
$$

where $w_{i}$ is the area swept for sample $i$. Random fields for positive catches are defined in the

same way as probability of occupied habitat.

The total abundance across the entire modeled spatial domain can then be calculated by summing up the total abundance of all the knots:

$$
\begin{aligned}
\hat{b}_{t}= & \sum_{j=1}^{n_{j}} a_{j} \operatorname{logit}^{-1}\left(\hat{d}_{t}^{(p)}+\sum_{k=1}^{n_{x}} \hat{\beta}_{k}^{(p)} x_{j, k}+\widehat{\omega}_{j}^{(p)}+\hat{\varepsilon}_{j, t}^{(p)}\right)_{i} \exp \\
& \left(\hat{d}_{t}^{(\lambda)}+\sum_{k=1}^{n_{x}} \hat{\beta}_{k}^{(\lambda)} x_{j, k}+\widehat{\omega}_{j}^{(\lambda)}+\hat{\varepsilon}_{j, t}^{(\lambda)}\right),
\end{aligned}
$$

where $\hat{b}_{t}$ is the total abundance in year $t, \hat{d}_{t}^{(p)}, \hat{\beta}_{k}^{(p)}, \hat{d}_{t}^{(\lambda)}$, and $\hat{\beta}_{k}^{(\lambda)}$ are fixed effects in the model and $\widehat{\omega}_{j}^{(p)}, \hat{\varepsilon}_{j, t}^{(p)}, \widehat{\omega}_{j}^{(\lambda)}$, and $\hat{\varepsilon}_{j, t}^{(\lambda)}$ are random effects in the model.

\section{Application to northern shrimp}

Northern shrimp in the GOM are at the southern extent of their range, concentrated in the southwestern region of the Gulf (Haynes and Wigley 1969; Clark et al. 1999). They are protandric hermaphrodites, maturing first as males and then transforming to females (Berkely 1931; Bergstrom 2000). In the GOM, northern shrimp are most frequently found in depths less than 300m (Haynes and Wigley 1969), with juveniles and immature males inhabiting shallower, inshore waters and adults occupying deeper offshore waters (Apollonio and Dunton 1969; Haynes and Wigley 1969; Apollonio et al. 1986). Factors that might influence shrimp 
193 distribution include water temperature, salinity, depth, and substrate type (Haynes and Wigley

194 1969; Shumway et al. 1985; Apollonio et al. 1986).

195 We applied the spatio-temporal generalized linear mixed model to data collected from a

196 summer shrimp bottom trawl survey, which is designed specifically for monitoring northern

197 shrimp in the western GOM, operated with consistent sampling protocol by the Northeast

198 Fisheries Science Center in cooperation with the Atlantic States Marine Fisheries Commission

199 from 1984 to 2013. A stratified random sampling design is used to select stations sampled during

200 the survey. The survey area is divided into 12 strata and stratification is based primarily on depth,

201 latitude/longitude, and historical fishing patterns (Figure 1; Clark 1989). However, additional

202 fixed stations are also visited each year. Design-based indices of abundance and biomass for

203 stock assessment are derived from data collected at the random stations within six strata (i.e.,

204 strata 1, 3, 5, 6, 7, and 8; Figure 1) that have been sampled most intensively and consistently

205 over time. Extreme fluctuations have been observed in the design-based survey indices in recent

206 years, including a spike in the 2006 abundance estimate (see NEFSC 2014, Figure C5. 12.). Such

207 high variability could not be explained by the stock assessment models, which was one of the

208 reasons that the recent assessment was not successful for northern shrimp in the GOM (NEFSC

209 2014). In this study, we included all the data from the summer survey including non-random

210 stations in the spatio-temporal model assuming that the process of selecting sampling locations is

211 independent of the process generating differences in population density (Diggle et al. 2010).

212 We overlaid a $2 \mathrm{~km} \times 2 \mathrm{~km}$ grid on the entire survey spatial domain, which resulted in

2134977 grid cells. For each cell we extracted the centroid and recorded the corresponding eastings

214 and northings. The value of the random field in each cell was assumed to be equal to its value at

215 the nearest knot according to the piecewise constant approximation. The value of covariates for a 
216 given knot is the average value of the covariates for all grids that are closest to the knot. The area

217 of a given knot can be calculated as the summation of areas of all the grid cells associated with it.

219 Habitat covariates and model selection

220 We included two static habitat variables (depth and sediment grain size), and two

221 dynamic habitat variables (bottom temperature and bottom salinity) to estimate the occurrence

222 and positive model. We assume that these static and dynamic habitat variables are the primary

223 drivers of spatial variation of shrimp distribution (Shumway et al. 1985; Apollonio et al. 1986;

224 Clark et al. 2000). During spring through autumn, adult shrimp are distributed primarily in

225 depths between $90 \mathrm{~m}$ and $180 \mathrm{~m}$ (Clark et al. 2000). Temperature may impose restrictions on the

226 amount of available habitat for northern shrimp in the GOM as seasonal bottom water

227 temperatures in some areas can exceed the preferred range $\left(0-5^{\circ} \mathrm{C}\right.$, Shumway et al. 1985 ;

228 Mountain and Jessen 1987). Adult shrimp are thought to seek deep basins as cold water refuges

229 (Apollonio et al. 1986), therefore depth is likely to explain some variation in shrimp spatial

230 distribution. Northern shrimp prefer an organic-rich muddy bottom (Hjort and Ruud 1938;

231 Bigelow and Schroeder 1939; Wigley 1960; Haynes and Wigley 1969), but they are not limited

232 to this habitat (Schick 1991). Depth and bottom temperature were recorded at each station in the

233 survey; however, we used habitat data which are available for the entire spatial domain from

234 other sources. Depth data were from U. S. Geological Survey, Coastal and Marine Geology

235 Program (http://pubs.usgs.gov/of/1998/of98-801/bathy/data.htm). Sediment grain size was

236 obtained from U. S. Geological Survey Open-File Report 2005-1001

237 (http://woodshole.er.usgs.gov/openfile/of2005-1001/htmldocs/datacatalog.htm\#surficial 
238 sediment). The Finite-Volume Community Ocean Model (FVCOM) was used to produce bottom

239 temperature and bottom salinity data (Chen et al. 2006).

240 We only considered the habitat covariates as main effects and did not consider any

241 interactions among the covariates. For dynamic habitat variables, i.e., bottom temperature and

242 bottom salinity, effects on the response variable were assumed to be constant across years. Each

243 of the covariates was standardized to have mean of zero and unit variance prior to inclusion in

244 the model. This facilitates the interpretation of their coefficients via comparison with others in

245 the model. The value of covariates in each knot was calculated as the average values in the area

246 associated with the knot. Models with and without covariates were compared to evaluate if

247 inclusion of covariates would improve the model fit and provide more accurate and precise

248 estimates of abundance. This also allowed us to identify which habitat variable has the largest

249 influence over shrimp spatial density. We looked at whether inclusion of habitat variables

250 decreased the marginal standard deviation (MSD) of spatial and spatio-temporal variables (see

251 Thorson et al. 2015, Appendix A for details of calculating MSD). We also calculated the pseudo-

$252 \mathrm{R}^{2}$ to determine the proportion of variance from the null model (i.e., the model has no habitat

253 variables) that was explained by including habitat variables. To do so, we compared the sum of

254 spatial and spatio-temporal variance from the null model with the same value from a model that

255 included habitat variables, and calculated the reduction in variance (pseudo- $\mathrm{R}^{2}$ ) as:

$$
\text { pseudo } R^{2}=1-\frac{\sigma_{\omega, m}^{2}+\sigma_{\varepsilon, m}^{2}}{\sigma_{\omega, \text { null }}^{2}+\sigma_{\varepsilon, \text { null }}^{2}}
$$

257 where subscript $m$ and null indicate a particular model $m$ and the null model, respectively. 
The model includes both fixed effects (i.e., year and habitat covariates) and random

261 effects (i.e., random fields). Fixed-effect parameters were estimated by identifying their values

262 that maximized the marginal likelihood function. We used Template Model Builder (TMB,

263 Kristensen et al. 2016), which approximates the marginal likelihood using the Laplace

264 approximation and then calculates the gradient of the marginal likelihood with respect to all

265 fixed effects. The probability of random fields was approximated using the stochastic partial

266 differential equation approach (Lindgren et al. 2011), as explained in detail in Thorson et al.

267 (2015). The marginal likelihood was maximized using conventional gradient-based non-linear

268 optimization in the R statistical platform (R Core Development Team 2013). The bias of derived

269 quantities (e.g., $\hat{b}_{t}$ ) caused by transforming nonlinear function of fixed and random effects was

270 accounted for by using a newly developed bias-correction algorithm. Further details can be found

271 in Thorson and Kristensen (2016). We used R package SpatialDeltaGLMM to estimate all the

272 parameters of the spatio-temporal index standardization model (https://github.com/nwfsc-

273 assess/geostatistical_delta-GLMM).

\section{Comparison between model-based and design-based indices}

276 We compared the performance of a stock assessment model for northern shrimp when fit

277 with spatio-temporal indices and design-based indices (stratified mean). The model was a

278 seasonal size-structured assessment model developed for hermaphroditic Pandalidae (Cao et al.

279 2016) and first vetted in a northern shrimp benchmark stock assessment (NEFSC 2014). The

280 spatio-temporal index used to fit the assessment model was derived from the estimated densities

281 restricted to the same six strata used to estimate the design-based index. We compared model fit

282 and retrospective patterns for spawning stock biomass and recruitment produced by the 
283 assessment model using both spatio-temporal and design-based indices. Retrospective bias was

284 quantified using a revised rho statistic of Mohn (1999) (Hurtado-Ferro et al. 2014). We also

285 evaluated the discrepancy between model outputs (i.e., spawning stock biomass and recruitment)

286 and biological reference points estimated based on spatio-temporal and design-based indices.

287 Spawning potential ratio-based metrics were calculated to determine the stock status for both

288 assessments using spatio-temporal and design-based indices.

290 the predictive performance of the size-structured assessment model using design-based and

291 spatio-temporal indices. One-year-ahead abundance index was forecasted based on the estimates

292 from the stock assessment with a series of fits in which $y=1, \ldots, 13$ years of data are left out at

293 the end. Relative error was calculated to quantify the disparity between model forecast and the

294 observed index for a given year:

$$
R E_{y}=\frac{I_{2014-y}^{p r e d}-I_{2014-y}^{o b s}}{I_{2014-y}^{o b s}}
$$

296 where $I_{2014-y}^{\text {pred }}$ is the median forecasted value in log-space for year 2014-y and $I_{2014-y}^{o b s}$ is the

297 design-based or spatio-temporal index in log-space for year 2014-y. Uncertainty in the forecasted

298 abundance index arises from uncertainty in estimated recruitment of the forecasting year.

299 Average absolute relative error was calculated for comparing the model predictive performance

300 with design-based and spatio-temporal indices:

$301 \quad A R E=\frac{\sum_{y=1}^{13}\left|R E_{y}\right|}{13}$ 
The estimated MSD was very close to zero for spatial and spatio-temporal variation in

305 "true" zeros (i.e., $\omega^{(p)}$ and $\left.\varepsilon^{(p)}\right)$. Therefore, we turned off the random fields for modeling the

306 probability of occupied habitat (i.e., $\omega^{(p)}$ and $\left.\varepsilon^{(p)}\right)$. Including habitat variables did not decrease

307 the MSD of spatio-temporal variation $\left(\sigma_{\varepsilon}^{(\lambda)}\right)$. However, it slightly reduced the MSD of spatial

308 variation $\sigma_{\omega}^{(\lambda)}$ (Table 1). In combination, habitat variables explained $25.9 \%$ of spatial and spatio-

309 temporal variation, which suggests that these habitat variables have an important impact on (but

310 do not by themselves fully explain) spatial variation in shrimp density. In general, spatial

311 variation that is constant over time has a greater magnitude than spatial variation that changes

312 annually. Therefore, we identified the model included depth, sediment grain size and salinity as

313 covariates, which had the lowest MSD for spatial variation and highest pseudo- $\mathrm{R}^{2}(0.262)$, as the

314 base model for further analysis.

315 Comparison of the MSDs of spatial and spatio-temporal variation estimated from the

316 model with and without each habitat variable indicates that the largest portion of the decreased

317 spatial variation for shrimp densities was explained by sediment grain size (Table 1), so we

318 concluded that this variable had the most significant impact on shrimp densities. Salinity, by

319 itself, did not lead to decreased spatial variation but made an important contribution in the

320 presence of other habitat variables. Temperature, alone or in the presence of other variables, did

321 not contribute to the decreased spatial variation for shrimp densities.

322 The spatio-temporal variation in shrimp density is shown in Figure 2, estimated from the

323 base model. The highest densities were generally found in the vicinity of Jeffreys Ledge, while

324 the lowest densities were found in the southeast of Cape Cod and southeast boundary of the

325 survey area (Figure 2). However, shrimp densities dropped dramatically in the recent two years,

326 especially for the southern portion of the survey domain where almost no shrimp could be found. 
327 The model's raw residuals did not show a strong spatial pattern over years (Figure 3). However,

328 the model fits to data after 2005 were worse than the fits to data from years prior. The estimated

329 anisotropy for the model component for positive catches showed that spatial residuals in positive

330 catches were stretched along the Northeast - Southwest, suggesting that densities are correlated

331 over a longer distance moving along the shoreline than perpendicular to the shoreline.

332 We next compared the estimated spatio-temporal and design-based indices. Given that

333 the assessment model freely estimates the catchability coefficient associated with this index, the

334 only information it provides is regarding relative trends. We therefore standardize all indices

335 prior to comparing them. The design-based index showed greater temporal variation than the

336 spatio-temporal index. The spatio-temporal indices for 2006 were much lower than the

337 corresponding design-based index (spatio-temporal indices: 3.92; design-based index: 6.86).

338 However, the design-based and spatio-temporal indices showed similar temporal trends, except

339 some minor discrepancies during the early time period (Figure 4). Trends in spatio-temporal

340 indices calculated based on six strata and the entire area were almost identical (Figure 4).

341 We then fit the size-structured assessment model using the estimated spatio-temporal

342 index (based on six strata) and compared the results with those obtained from the model using

343 the design-based index. The results showed improvement in the assessment model fit overall

344 (total likelihood decreased from 9971.02 to 9945.33). More specifically, there was a substantial

345 decrease in the likelihood of the abundance index (from 17.993 to -6.795 ). The predicted

346 abundance index from the assessment model was within or very close to the $95 \%$ interval of the

347 centered spatio-temporal index for every year (Figure 5a). However, the assessment model

348 prediction disagreed with the design-based index for some years, e.g., 1994, 2006 and 2007

349 (Figure 5b). More importantly, the assessment model based on the design-based index failed to 
350 capture the spike observed in the design-based index of 2006 (Figure 5b). However, the 351 assessment model using the spatio-temporal index captured this variation reasonably well

352 (Figure 5a). This suggests that the index derived from the spatio-temporal model provided more

353 consistent information with other assessment data inputs (e.g., total catch, catch and survey

354 compositions). Improvement in model diagnostics when using the spatio-temporal index was

355 also found in retrospective patterns. Retrospective pattern was reduced when the assessment

356 model was fitted to the spatio-temporal index (Figure 6). Revised Mohn's rho, measured for

357 estimated spawning stock biomass and recruitment, reduced by $66.7 \%$ and $20 \%$, respectively,

358 when the spatio-temporal index was used in the assessment model.

359 We also compared the outputs from assessment models (i.e., estimated recruitment and

360 spawning stock biomass) using the spatio-temporal and design-based indices. Both recruitment

361 and spawning stock biomass estimates based on the spatio-temporal index were more than 50\%

362 larger than those based on design-based index for the recent years, i.e., 2010 - 2013 (Figure 7),

363 which are of high importance to managers. On average, spawning stock biomass was more

364 sensitive to the changes in abundance index than recruitment, and spawning stock biomass

365 estimates based on the design-based index were larger than those based on the spatio-temporal

366 index on average. Proxy reference points based on spawning potential ratio were calculated to

367 determine the stock status. $\mathrm{F}_{40 \%}$ based on spatio-temporal and design-based indices were 0.78

368 and 0.83 , respectively. Forty percent of unexploited spawning stock biomass based on spatio-

369 temporal and design-based indices were 2375.9 and $2433.3 \mathrm{mt}$, respectively. Historical stock

370 status determined based on design-based index was more optimistic than that based on spatio-

371 temporal index (Figure 8). 
Finally, we evaluated the predictive performance of assessment models (i.e., forecasting

373 one-year-ahead abundance index) using spatio-temporal and design-based indices. On average,

374 the assessment model using the spatio-temporal index performed better in forecasting the one-

375 year-ahead abundance index ( $A R E$ for spatio-temporal index: $0.52 ; A R E$ for design-based index:

376 0.62) (Figure 9). The assessment model using the design-based index did not converge when

377 forecasting the abundance index for years 2005, 2010, 2012 and 2013. However, the assessment

378 model using the spatio-temporal index successfully forecasted the abundance indices for all the

37913 years. The models showed similar performance in forecasting abundance indices of 2002,

3802008 and 2011, but for 2001, 2004 and 2009 the model using the design-based index had relative

381 error closer to zero than the model using spatio-temporal index (Figure 9). However, the

382 assessment model using the spatio-temporal index greatly outperformed the model using the

383 design-based index in forecasting abundance indices of 2006 and 2007 when the abundance

384 indices showed large temporal variation.

\section{DISCUSSION}

In this study, we evaluated a potential improvement to a size-structured assessment

388 model for northern shrimp in the GOM. We showed that using a spatio-temporal abundance

389 index (rather than an abundance index derived from classical design-based estimators) resulted in

390 improved predictive performance (from a one-step-ahead predictive evaluation) and

391 retrospective performance (using Mohn's rho). We therefore conclude that using the spatio-

392 temporal index resulted in improvements in assessment model performance for this stock. The

393 spatio-temporal and design-based estimators resulted in particularly large differences in 2006,

394 but otherwise had similar abundance trends. Despite these similarities in abundance trends, 
395 utilizing the spatio-temporal index in the assessment model greatly alters the estimates of 396 recruitment and spawning stock biomass, especially for the recent years (Figure 7), and also 397 alters the determination of stock status for some years (Figure 8). Based on the spawning 398 potential ratio-based metrics, the assessment using a design-based estimator leads to a more 399 optimistic perception of historical stock status for northern shrimp in the GOM (Figure 8). 400 Spatially correlated variation in density is observed in almost all fisheries data collected 401 from both fishery-dependent and fishery-independent sources (Booth 2000). However, spatial 402 variation is often ignored or not properly dealt with in statistical analysis and inference.

403 Consequently, it results in inaccurate and imprecise estimates of relative abundance (Swartzman 404 et al. 1992; Petitgas 1993) and/or misleading interpretations of various aspects of a species' 405 biology (Thorson 2015). By contrast, the spatio-temporal index standardization can provide a 406 more precise abundance index than design-based estimator or conventional models by explaining 407 spatial variation in densities (Shelton et al. 2014; Thorson et al. 2015). Specifically, densities in 408 different locations are assumed to have distinct expected values based on habitat covariates and 409 spatial terms, and densities at nearby sites are more similar than densities at geographically 410 remote sites. In contrast, design-based estimator assumes that the mean of a given stratum is 411 fixed and all locations within that stratum provide exchangeable samples of a single mean. Thus, 412 the design-based estimator is often more sensitive to outlier observations (Shelton et al. 2014).

413 This effect can be particularly significant in conjunction with decreasing sampling effort. This 414 might be the reason that the centered design-based index of 2006 is much larger than 415 corresponding spatio-temporal index in this study. The number of sampling locations used to 416 derive the design-based index in 2006 (29) is smaller than other years (40 - 50), and 5 out of 29 417 sampling locations fell in 'hot spots' which had one order of magnitude higher tows than average. 
418 In this case, relative abundance estimates can benefit greatly from filling spatial gaps (i.e.,

419 predicting un-sampled locations) using a spatio-temporal model.

420 We included habitat covariates in the spatio-temporal model to capture the important

421 structure in the mean. This could partially account for the non-stationarity which could arise

422 from two sources. However, we did not use non-stationary Gaussian random fields in our study

423 because a previous study suggested that non-stationary Gaussian random fields are not always

424 necessary to model non-stationary spatial data (Fuglstad et al. 2015). We have shown that

425 including depth, sediment grain size and salinity as covariates in the model explained

426 approximately $26.2 \%$ percent of spatial and spatio-temporal variation relative to the model that

427 had no habitat variables, and did so by decreasing the spatial (constant over time) component.

428 Northern shrimp prefer fine-grained sediments according to our study, perhaps because they

429 provide more food, e.g., soft bottom benthic invertebrates. Depth had a positive effect on shrimp

430 density as deeper basins are thought to provide cold water refuges (Apollonio et al. 1986). These

431 results are consistent with previous studies (Haynes and Wigley 1969; Shumway et al. 1985).

432 The range of salinity fields used in the model was relatively narrow $(31.3-35.0 \mathrm{psu})$, which is

433 well within the salinity range reported in the previous study (Shumway et al. 1985). Within that

434 range of salinity, our study indicated that shrimp prefer slightly lower salinity in the study area.

435 However, bottom temperature did not contribute to explaining spatial variation in our study,

436 despite its well-documented influence on shrimp population dynamics in this region (Apollonio

437 et al. 1986; Richards et al. 2012; Richards et al. 2016). Summer bottom temperatures in shrimp

438 habitat areas have remained several degrees cooler than upper thermal tolerance levels for adult

439 northern shrimp (Shumway et al. 1985; Bergstrom 2000), even with warming in recent years.

440 Thus the thermal gradient may have been too weak during the study period to influence the 
441 distribution of shrimp. Also, it is possible that the effect of temperature on shrimp density is at

442 much finer spatial scale which could not be well approximated by the knots. To evaluate this

443 possibility, we calculated the percentage of total variance in the habitat variables that was

444 explained by variance among knots. The results showed that except for depth (72\%) the

445 percentages for other variables are about 50\%, suggesting that fine-scale variability of habitat

446 covariates was not used in the model.

447 Additionally, our spatio-temporal model, which can be considered as an extension of

448 generalized linear model, assumes that the relationship between habitat and response variables is

449 linear. Thus, the model would need to be modified to account for dome-shaped or saturating

450 relationships between habitat variables and shrimp density. We avoided adding polynomial

451 expansion $\mathrm{x}^{2}, \mathrm{x}^{3}$ and interaction terms to the model because of the risk of overfitting and the

452 extensive cross-validation testing required to avoid overfitting. Using a habitat suitability index

453 as the only habitat covariate in the spatio-temporal model might better explain the spatial

454 variation while keeping the model parsimonious (Breece et al. 2016).

455 We also note that sampling intensity in marginal strata changed over time as a result of

456 preferential sampling that led to the over-sampling locations corresponding to high densities (i.e.,

457 strata used to derive design-based index). The standard deviations of predicted densities were

458 high in the area where sampling intensity was low (Figure S1). Therefore, we cannot eliminate

459 the possibility that model-based inference for the entire survey domain is biased. However, we

460 used the spatio-temporal index derived from six strata for comparison, so the conclusions of this

461 study are less likely to be influenced by violating the model assumption of non-preferential

462 sampling. We suggest that future research could explore the spatio-temporal models for

463 preferential sampling (Diggle et al. 2010). The spatio-temporal abundance index was estimated 
464 from the spatio-temporal model based on the data including non-random stations. However,

465 excluding the data from non-random stations did not appreciably change the abundance estimates

466 (Figure S2).

467 We envision several important topics for future applications of spatio-temporal

468 estimation methods. Most importantly, spatio-temporal methods could be used to estimate

469 density for different size or age-classes of fishes and invertebrates (Kristensen et al. 2014). These

470 estimates could then be processed to generate age or size-composition data for assessment

471 models. A model-based approach to estimating age- or size-composition may be more

472 statistically efficient for species with spatial segregation of size or age groups (e.g. life history

473 stages). This spatial predictability is not currently used by design-based or stratified approaches

474 to compositional standardization (Thorson 2014). For example, if male northern shrimp are

475 preferentially distributed in shallow waters, then we expect that design-based estimates of size

476 composition would be skewed towards male due to the preferential random allocation of sample

477 locations (i.e., sampled most intensively in strata 1, 3, 5, 6, 7, and 8). Compositional data have a

478 strong effect on assessment results for many species (for better or worse; Francis 2011), so we

479 highly recommend methods to improve statistical efficiency for these data.

480 We also recommend continuing research to improve statistical efficiency when

481 estimating abundance trends from survey samples. We note that multispecies data are a generally

482 under-utilized source of information regarding habitat suitability. In particular, detecting a

483 species with similar habitat preferences may be informative about the likely density of a target

484 species (Thorson et al. 2015). We therefore suspect that jointly analyzing survey catch rates for

485 multiple species may improve density estimates for rare or poorly-sampled species. Planned

486 surveys following a randomized design continue to be the most reliable source of information 
487 regarding stock status for fisheries worldwide. We therefore encourage any research that allows 488 better inference to be made using limited historical and expensive ongoing surveys.

\section{ACKNOWLEDEGEMENTS}

492 Financial support for this study was provided by the Maine Sea Grant Program, the Maine

493 Department of Marine Resources and the NOAA FATE program. We thank Margaret Hunter and 494 the Atlantic States Marine Fisheries Commission Northern Shrimp Technical Committee for 495 informative discussions on the northern shrimp stock assessment and for providing the data on 496 which this study is based. 


\section{REFERENCES}

498 Apollonio, S., and Dunton, E.E. 1969. The northern shrimp, Pandalus borealis, in the Gulf of 499 Maine. Completion Rept., ME Dept. Sea and Shore Fisheries, Proj. 3-12-R, 81p.

500 Apollonio, S., Stevenson, D., and Dunton, E.E. 1986. Effects of temperature on the biology of 501 the northern shrimp, Pandalus borealis, in the Gulf of Maine. NOAA Tech. Rep. NMFS 42.

502 Available online at: http://spo.nwr.noaa.gov/tr42.pdf

503 Bigelow, H.A., and Schroeder, W.C. 1939. Notes on the fauna above mud bottoms in deep water 504 in the Gulf of Maine. Biol. Bull. (Woods Hole) 76: 305-324.

505 Booth, A.J. 2000. Incorporating the spatial component of fisheries data into stock assessment 506 models. ICES J. Mar. Sci. 57(4): 858-865.

507 Breece, M.W., Fox, D.A., Dunton, K.J., Frisk, M.G., Jordaan, A. and Oliver, M.J. 2016.

508 Dynamic seascapes predict the marine occurrence of an endangered species: Atlantic Sturgeon 509 Acipenser oxyrinchus oxyrinchus. Methods Ecol. Evol. 7: 725-733.

510 Cao, J., Chen, Y., Chang, J.H., and Chen, X. 2014. An evaluation of an inshore bottom trawl

511 survey design for American lobster (Homarus americanus) using computer simulations. J.

512 Northwest Atl. Fish. Sci. 46: 27-39.

513 Cao, J., Chen, Y., Richards, A. 2017. Improving assessment of Pandalus stocks using a seasonal,

514 size-structured assessment model with environmental variables: Part I: Model description and 515 application. Can. J. Fish. Aquat. Sci. 74(3): 349-362.

516 Chen, C., Beardsley, R.C., Cowles, G.W. 2006. An unstructured-grid, finite-volume coastal 517 ocean model (FVCOM) system. Oceanography 19: 78-89. 
518 Clark, S.H. 1989. State-Federal northern shrimp survey. In: Proceedings of a workshop on

519 bottom trawl surveys. Azarovitz, T.R., McGurrin, J. and Seagraves, R. (eds.). ASMFC Spec.

520 Rept. 17: 27-29.

521 Clark, S.H., Cadrin, S.X., Schick, D.F., Diodati, P.J., Armstrong, M.P., and McCarron, D. 2000.

522 The Gulf of Maine northern shrimp (Pandalus borealis) fishery: a review of the record. J.

523 Northw. Atl. Fish. Sci. 27: 193-226.

524 Cressie, N., and Wikle, C.K. 2011. Statistics for Spatio-Temporal Data. JohnWiley \& Sons.

525 Diggle, P.J., Menezes, R., and Su, T. 2010. Geostatistical inference under preferential sampling.

526 J. Roy. Statist. Soc. Ser. C 59: 191-232.

527 Francis, R.I.C.C., 2011. Data weighting in statistical fisheries stock assessment models. Can. J.

528 Fish. Aquat. Sci. 68: 1124-1138.

529 Fuglstad, G.A., Simpson, D., Lindgren, F. and Rue, H. 2015. Does non-stationary spatial data

530 always require non-stationary random fields? Spat. Stat.14: 505-531.

531 Haynes, E.B., and Wigley, R.L. 1969. Biology of the northern shrimp, Pandalus borealis, in the

532 Gulf of Maine. Trans. Am. Fish. Soc. 98(1): 60-76.

533 Helser, T.E., Punt, A.E., and Methot, R.D. 2004. A generalized linear mixed model analysis of a

534 multi-vessel fishery resource survey. Fish. Res. 70: 251-264.

535 Hjort, J., and Ruud, J.T. 1938. Deep-sea prawn fisheries and their problems. Hvalr. Skr. 17: 153644. 
537 Hurtado-Ferro, F., Szuwalski, C.S., Valero, J.L., Anderson, S.C., Cunningham, C.J., Johnson, K.

538 F., Licandeo, R., McGilliard, C.R., Monnahan, C.C., Muradian, M.L., Ono, K., Vert-Pre, K.A.,

539 Whitten, A.R., and Punt, A.E. 2014. Looking in the rear-view mirror: bias and retrospective

540 patterns in integrated, age-structured stock assessment models. ICES J. Mar. Sci. 72: 99-110.

541 Kristensen, K., Thygesen, U.H., Andersen, K.H., and Beyer, J.E. 2014. Estimating spatio-

542 temporal dynamics of size-structured populations. Can. J. Fish. Aquat. Sci. 71: 326-336.

543 Kristensen, K., Nielsen, A., Berg, C.W., Skaug, H., and Bell, B.M. 2016. TMB: Automatic

544 Differentiation and Laplace Approximation. J. Stat. Softw. 70(5): 1-21.

545 Lindgren, F., Rue, H., and Lindstrom, J. 2011. An explicit link between Gaussian fields and 546 Gaussian Markov random fields: the stochastic partial differential equation approach. J. Roy.

547 Statist. Soc. Ser. B 73: 423-498.

548 Martin, T.G., Wintle, B.A., Rhodes, J.R., Kuhnert, P.M., Field, S.A., Low-Choy, S.J., Tyre, A.J.

549 and Possingham, H.P., 2005. Zero tolerance ecology: improving ecological inference by

550 modelling the source of zero observations. Ecol. Lett. 8(11): 1235-1246.

551 Maunder, M.N., and Punt, A.E. 2004. Standardizing catch and effort data: a review of recent 552 approaches. Fish. Res. 70: 141-159.

553 Mountain, D.G., and Jessen, P.F. 1987. Bottom waters of the Gulf of Maine, 1978-1983. J. Mar. 554 Res. 45: 319-345.

555 Northeast Fisheries Science Center (NEFSC). 2014. $58^{\text {th }}$ Northeast Regional Stock Assessment 556 Workshop (58th SAW) Assessment Report. US Dept Commer, Northeast Fish Sci Cent Ref Doc. 
557 14-04; 784 p. Available from: National Marine Fisheries Service, 166 Water Street, Woods Hole, 558 MA 02543-1026, or online at http://nefsc.noaa.gov/publications/

559 Petitgas, P. 1993. Geostatistics for fish stock assessments: a review and an acoustic application.

560 ICES J. Mar. Sci. 50(3): 285-298.

561 R Core Development Team. 2013. R: A Language and Environment for Statistical Computing. R 562 Foundation for Statistical Computing, Vienna, Austria. http://www.R-project.org/.

563 Richards, R. A., Fogarty, M., Mountain, D., Taylor, M. 2012. Climate change and northern 564 shrimp recruitment variability in the Gulf of Maine. Mar. Ecol. Prog. Ser. 464: 167-178.

565 Richards, R.A., O’Reilly, J. E., Hyde, K.W.J. 2016. Use of satellite data to identify critical 566 periods for early life survival of northern shrimp in the Gulf of Maine. Fish. Oceanogr. 25(3): $567 \quad 306-319$.

568 Schick, D.F. 1991. Pandalid shrimp distribution relative to bottom type and availability to 569 commercial and research trawls in the Gulf of Maine. ICES C.M. 1991/K:8 p. 7.

570 Schnute, J.T., Boers, N., Haigh, R., Grandin, C., Johnson, A., Wessel, P., and Antonio, F. 2013.

571 PBSmapping: Mapping Fisheries Data and Spatial Analysis Tools. http://CRAN.R-

572 project.org/package=PBSmapping

573 Shelton, A.O., Thorson, J.T., Ward, E.J., and Feist, B.E. 2014. Spatial semiparametric models 574 improve estimates of species abundance and distribution. Can. J. Fish. Aquat. Sci. 71: 16555751666. 
576 Shumway, S.E., Perkins, H.C., Schick, D.F., and Stickney, A.P. 1985. Synopsis of the biological

577 data of the pink shrimp Pandalus borealis (Krøyer, 1938) FAO Fisheries Synopsis, No 144;

578 NOAA Tech. Rep., NMFS 30, 57p. Available online at: http://spo.nwr.noaa.gov/tr30.pdf

579 Skaug, H., and Fournier, D. 2006. Automatic approximation of the marginal likelihood in non-

580 Gaussian hierarchical models. Comput. Stat. Data An. 51: 699-709.

581 Smith, S. J. 1990. Use of statistical models for the estimation of abundance from groundfish

582 trawl survey data. Can. J. Fish. Aquat. Sci. 47: 894-903.

583 Swartzman, G., Huang, C., and Kaluzny, S. 1992. Spatial analysis of Bering Sea groundfish

584 survey data using Generalized Additive Models. Can. J. Fish. Aquat. Sci. 49: 1366-1378.

585 Thorson, J.T. 2014. Standardizing compositional data for stock assessment. ICES J. Mar. Sci. 71:

$586 \quad 1117-1128$.

587 Thorson, J.T. 2015. Spatio-temporal variation in fish condition is not consistently explained by

588 density, temperature, or season for California Current groundfishes. Mar. Ecol. Prog. Ser. 526:

$589 \quad 101-112$.

590 Thorson, J.T., and Kristensen, K. 2016. Implementing a generic method for bias correction in

591 statistical models using random effects, with spatial and population dynamics examples. Fish.

592 Res. 175: 66-74.

593 Thorson, J.T., Scheuerell, M.D., Shelton, A.O., See, K.E., Skaug, H.J., Kristensen, K., 2015.

594 Spatial factor analysis: a new tool for estimating joint species distributions and correlations in

595 species range. Methods Ecol. Evol. 6: 627-637. 
596 Thorson, J.T., Shelton, A.O., Ward, E.J., and Skaug, H.J. 2015. Geostatistical delta-generalized

597 linear mixed models improve precision for estimated abundance indices for West Coast

598 groundfishes. ICES J. Mar. Sci. 72(5): 1297-1310.

599 Thorson, J.T., and Ward, E. 2013. Accounting for space-time interactions in index

600 standardization models. Fish. Res. 147: 426-433.

601 Thorson, J.T., and Ward, E.J. 2014. Accounting for vessel effects when standardizing catch rates 602 from cooperative surveys. Fish. Res. 155: 168-176.

603 Wigley, R.L. 1960. Note on the distribution of Pandalidae (Crustacea, Decapoda) in New

604 England waters. Ecol. 41: 564-570.

605 Ye, Y., and Darren, D. 2009. How reliable are the abundance indices derived from commercial 606 catch-effort standardization? Can. J. Fish. Aquat. Sci. 66(7): 1169-1178. 
607 Table 1. Marginal standard deviation (MSD) of spatial and spatio-temporal variables and

608 pseudo- $\mathrm{R}^{2}$ showing the proportion of variance from the null model (i.e., the model with no

609 habitat covariates included) that is explained by including covariate(s) in the model. Note that

610 model with temperature and depth as covariates could not produce converged results. The

611 saturated model includes depth, sediment, temperature, and salinity as covariates. The model in

612 boldface is the base model.

\begin{tabular}{cccc}
\hline Model & \multicolumn{2}{c}{ Random fields (MSD) } & Pseudo-R \\
\hline Saturated model & $\sigma_{\omega}^{(\lambda)}$ & $\sigma_{\varepsilon}^{(\lambda)}$ & \\
\hline Saturated model - temperature & 0.705 & 0.215 & 0.259 \\
Saturated model - salinity & $\mathbf{0 . 7 0 4}$ & $\mathbf{0 . 2 1 4}$ & $\mathbf{0 . 2 6 2}$ \\
Saturated model - depth & 0.748 & 0.217 & 0.173 \\
Saturated model - sediment & 0.716 & 0.217 & 0.237 \\
Null model + depth + sediment & 0.757 & 0.213 & 0.157 \\
Null model + temperature + salinity & 0.752 & 0.215 & 0.166 \\
Null model + depth + salinity & 0.818 & 0.211 & 0.027 \\
Null model + temperature + depth & 0.760 & 0.212 & 0.151 \\
Null model + temperature + sediment & - & - & - \\
Null model + sediment + salinity & 0.742 & 0.217 & 0.185 \\
Null model + depth & 0.803 & 0.215 & 0.240 \\
Null model + sediment & 0.748 & 0.210 & 0.061 \\
Null model + temperature & 0.830 & 0.215 & 0.174 \\
Null model + salinity & 0.823 & 0.210 & 0.001 \\
Null model & 0.831 & 0.209 & 0.017 \\
\hline
\end{tabular}

$613 \overline{\sigma_{\omega}^{(\lambda)} \text { and } \sigma_{\varepsilon}^{(\lambda)} \text { are the MSDs of spatial and spatio-temporal random fields for the expected positive }}$

614 catches given occupied habitat, i.e., the standard deviation of different realizations of density

615 governed by the same stochastic process. 
FIGURE CAPTIONS

617

618 Figure 1. Northern shrimp summer survey area and strata in the Gulf of Maine (coastlines data

619 from R package ocedata).

620 Figure 2. Density of northern shrimp 1984 - 2013, estimated by the spatio-temporal generalized

621 linear mixed model. Predicted density is shown for the centroid of each $2 \mathrm{~km} \times 2 \mathrm{~km}$ grid cell.

622 Figure 3. The raw residuals (1984-2013) from the spatio-temporal generalized linear mixed

623 model. Positive and negative values are in red and blue circles, respectively.

624 Figure 4. Centered abundance indices derived from design-based and model-based spatio-

625 temporal approaches. Design-based index is calculated based on data from six strata (i.e., strata 1,

$6263,5,6,7$, and 8; Figure 1). Two spatio-temporal indices are estimated for different spatial areas

627 (i.e., strata 1, 3, 5, 6, 7, and 8 and all strata). Note that coefficients of variance $(\mathrm{CV})$ of

628 abundance indices derived from design-based and model-based spatio-temporal estimators

629 (based on six strata and all strata) are 1.20, 0.69, and 0.71, respectively.

630 Figure 5. Comparison of stock assessment model fits to (a) spatio-temporal index and (b)

631 design-based index. Points show predictions from stock assessment model and red lines

632 represent estimated abundance index with 95\% intervals for the (a) spatio-temporal model and

633 (b) design-based approach.

634 Figure 6. Retrospective analysis of spawning stock biomass and recruitment for assessment

635 based on design-based and spatio-temporal indices. The full assessment time series (line

636 extending through 2013) is compared with model runs of identical structure but with $1,2, \ldots, 8$

637 years of data removed (lines extending through 2005 to 2012) to illustrate retrospective bias, 
638 which is quantified by Mohn's $\rho$ (the value is zero when the peeled assessments match exactly

639 with full time series assessment).

640 Figure 7. Relative changes in percentage for estimated recruitment and spawning stock biomass

641 based on spatio-temporal and design-based indices. Note that the reference value is the estimates

642 based on design-based index (for values greater than the reference value, the relative change in

643 percentage should be a positive number).

644 Figure 8. Status of northern shrimp stock in the Gulf of Maine determined based on stock

645 assessment with (a) design-based index and (b) spatio-temporal index. The horizontal line (red

646 and yellow) represents $\mathrm{F}_{40 \%}$ (the fishing mortality at which spawning stock biomass per recruit is

$64740 \%$ of virgin level) and the area above the line indicates that overfishing is occurring. The

648 vertical line represents spawning stock biomass at $40 \%$ of virgin spawning stock biomass and the

649 area to the left indicates that the stock has been overfished.

650 Figure 9. Relative error of one-year-ahead forecast index based on assessment model using

651 design-based and spatio-temporal indices. Note that the assessment model using design-based

652 index fails to forecast the abundance index for years 2005, 2010, 2012 and 2013 because of non-

653 convergence. 


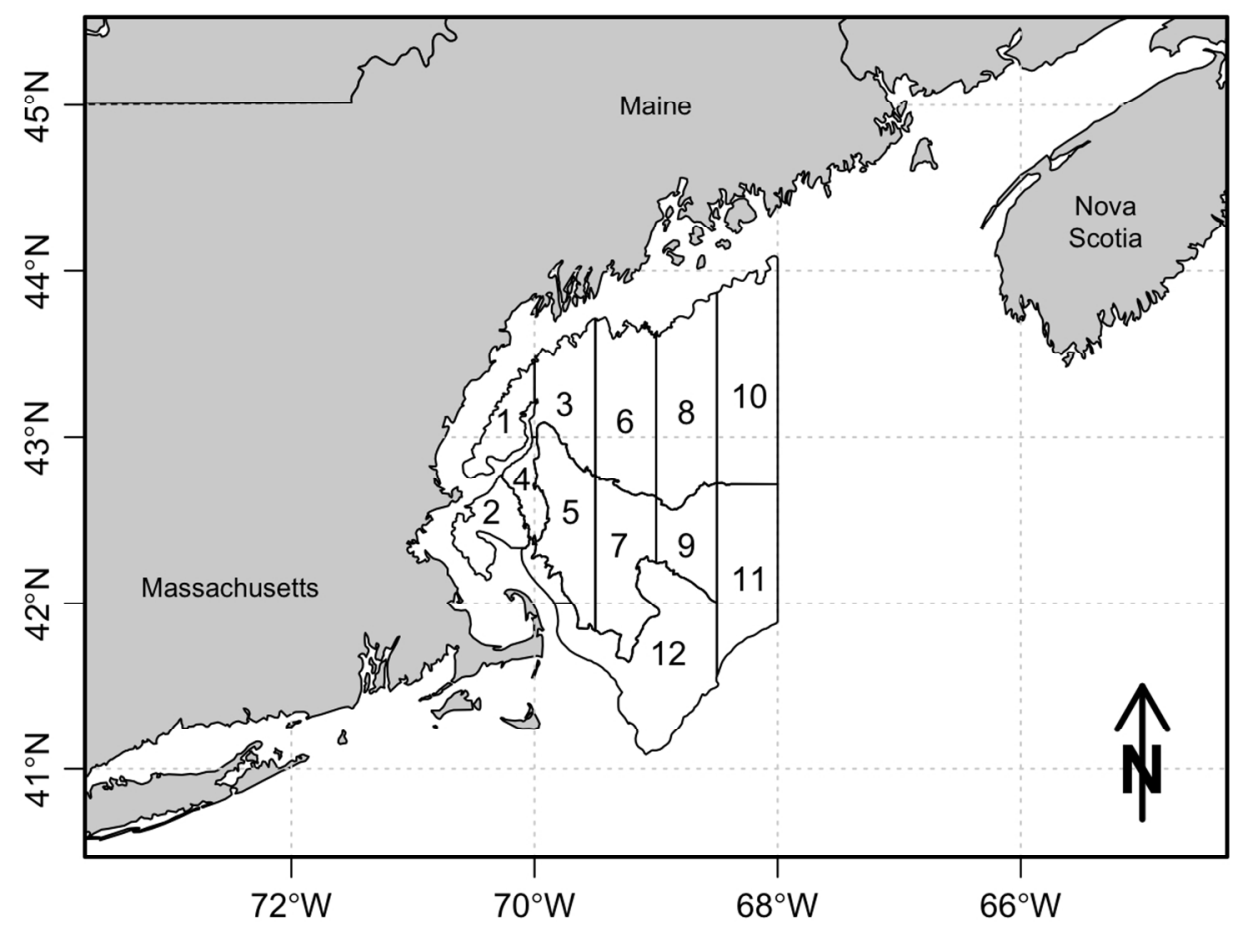

Figure 1. Northern shrimp summer survey area and strata in the Gulf of Maine (coastlines data from R package ocedata).

$458 \times 352 \mathrm{~mm}(72 \times 72 \mathrm{DPI})$ 


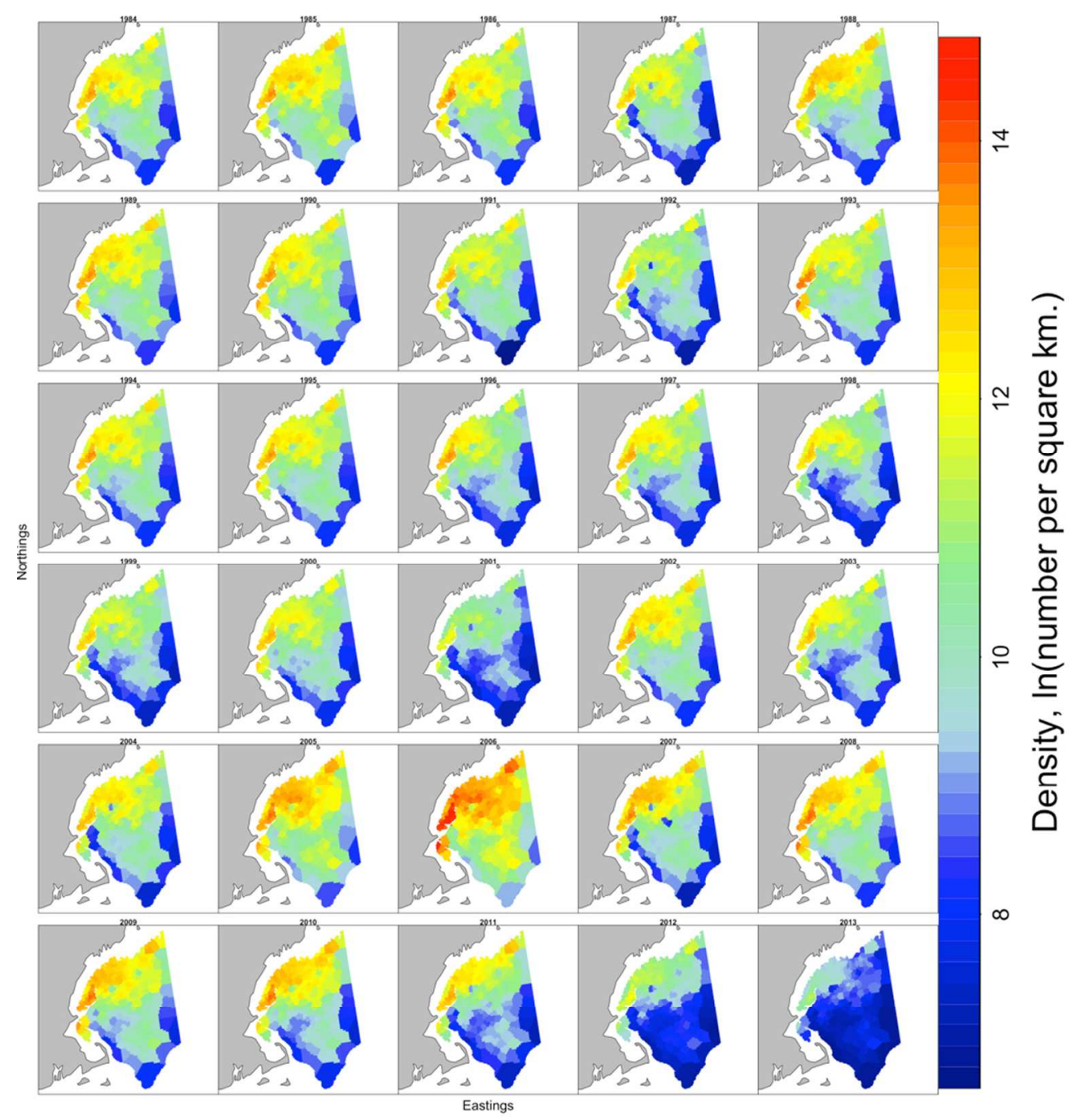

Figure 2. Density of northern shrimp $1984-2013$, estimated by the spatio-temporal generalized linear mixed model. Predicted density is shown for the centroid of each $2 \mathrm{~km} \times 2 \mathrm{~km}$ grid cell. 


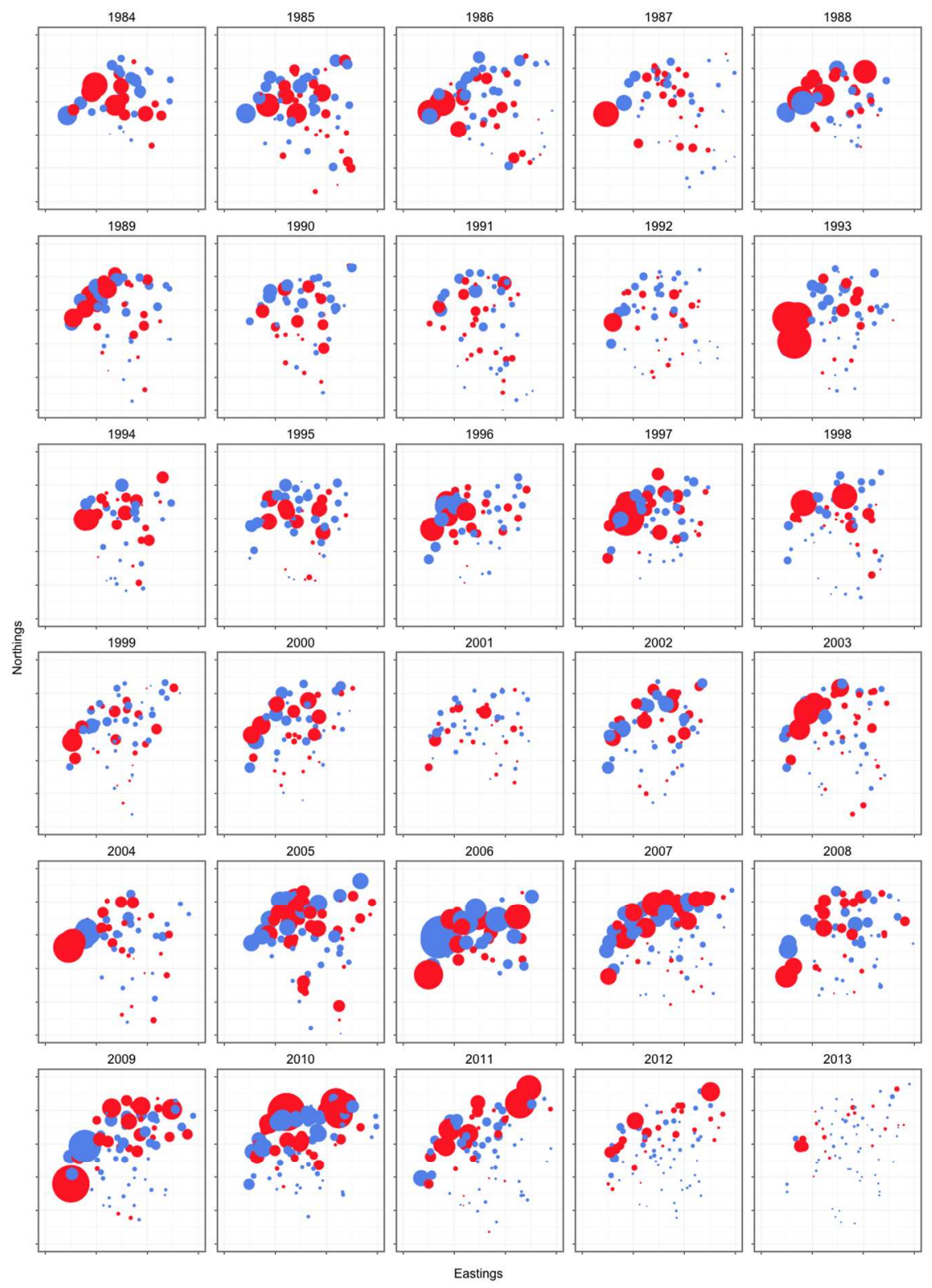

Figure 3. The raw residuals (1984 - 2013) from the spatio-temporal generalized linear mixed model. Positive and negative values are in red and blue circles, respectively.

$458 \times 635 \mathrm{~mm}(72 \times 72 \mathrm{DPI})$ 


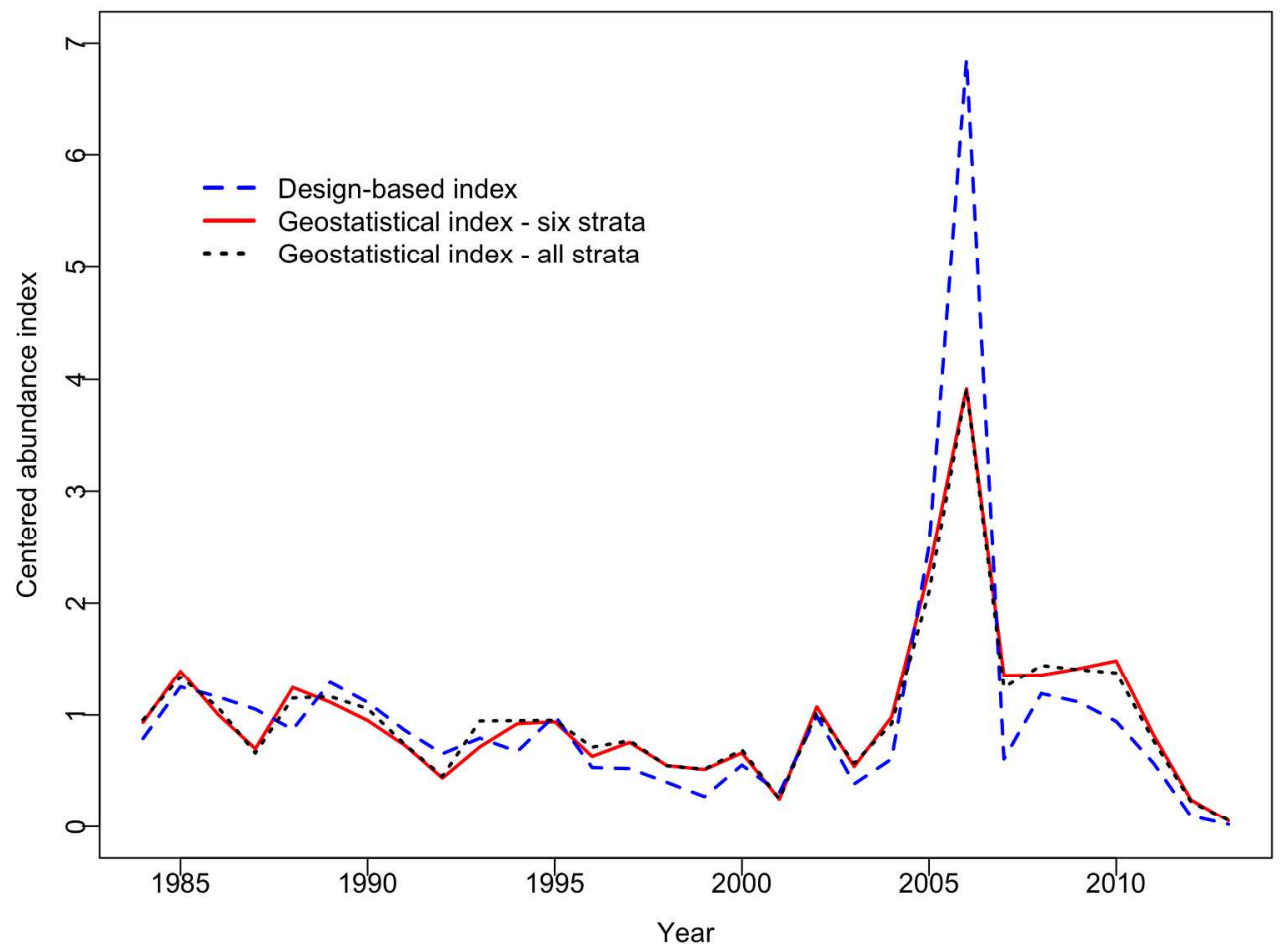

Figure 4. Centered abundance indices derived from design-based and model-based spatio-temporal approaches. Design-based index is calculated based on data from six strata (i.e., strata 1, 3, 5, 6, 7, and 8; Figure 1). Two spatio-temporal indices are estimated for different spatial areas (i.e., strata 1, 3, 5, 6, 7, and 8 and all strata). Note that coefficients of variance (CV) of abundance indices derived from design-based and model-based spatio-temporal estimators (based on six strata and all strata) are 1.20, 0.69, and 0.71, respectively.

$846 \times 635 \mathrm{~mm}(72 \times 72$ DPI $)$ 

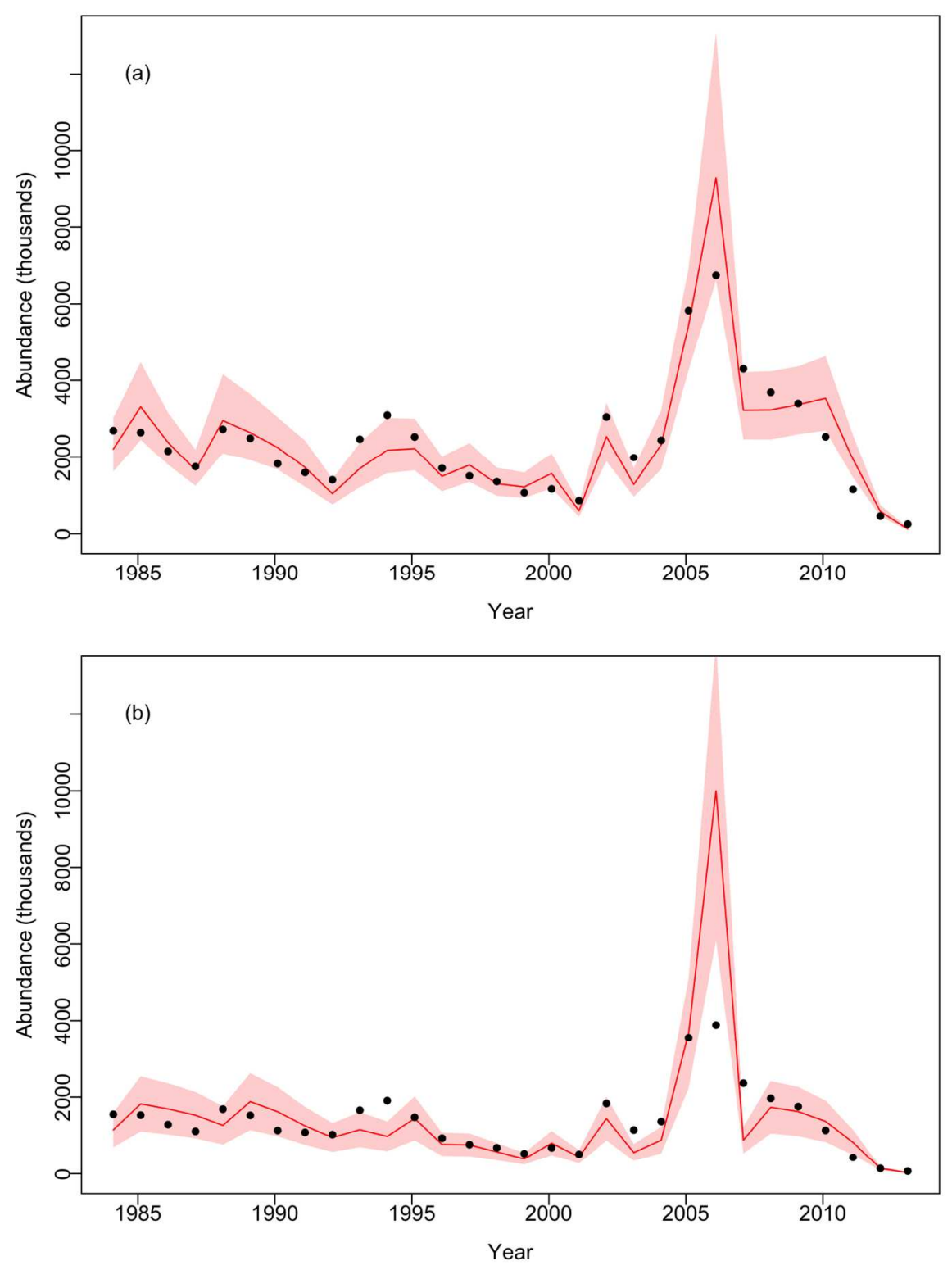

Figure 5. Comparison of stock assessment model fits to (a) spatio-temporal index and (b) design-based index. Points show predictions from stock assessment model and red lines represent estimated abundance index with $95 \%$ intervals for the (a) spatio-temporal model and (b) design-based approach. 


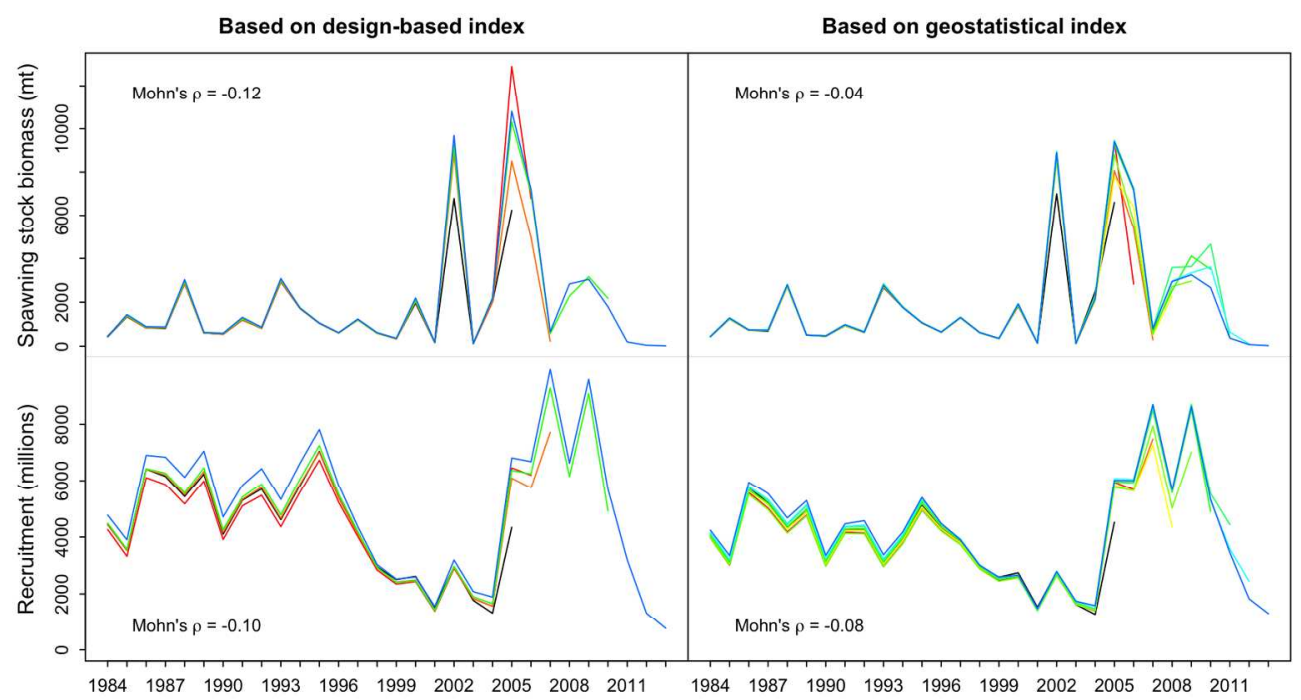

Figure 6. Retrospective analysis of spawning stock biomass and recruitment for assessment based on design-based and spatio-temporal indices. The full assessment time series (line extending through 2013) is compared with model runs of identical structure but with $1,2, \ldots, 8$ years of data removed (lines extending through 2005 to 2012) to illustrate retrospective bias, which is quantified by Mohn's $\rho$ (the value is zero when the peeled assessments match exactly with full time series assessment).

$705 \times 423 \mathrm{~mm}(72 \times 72$ DPI $)$ 


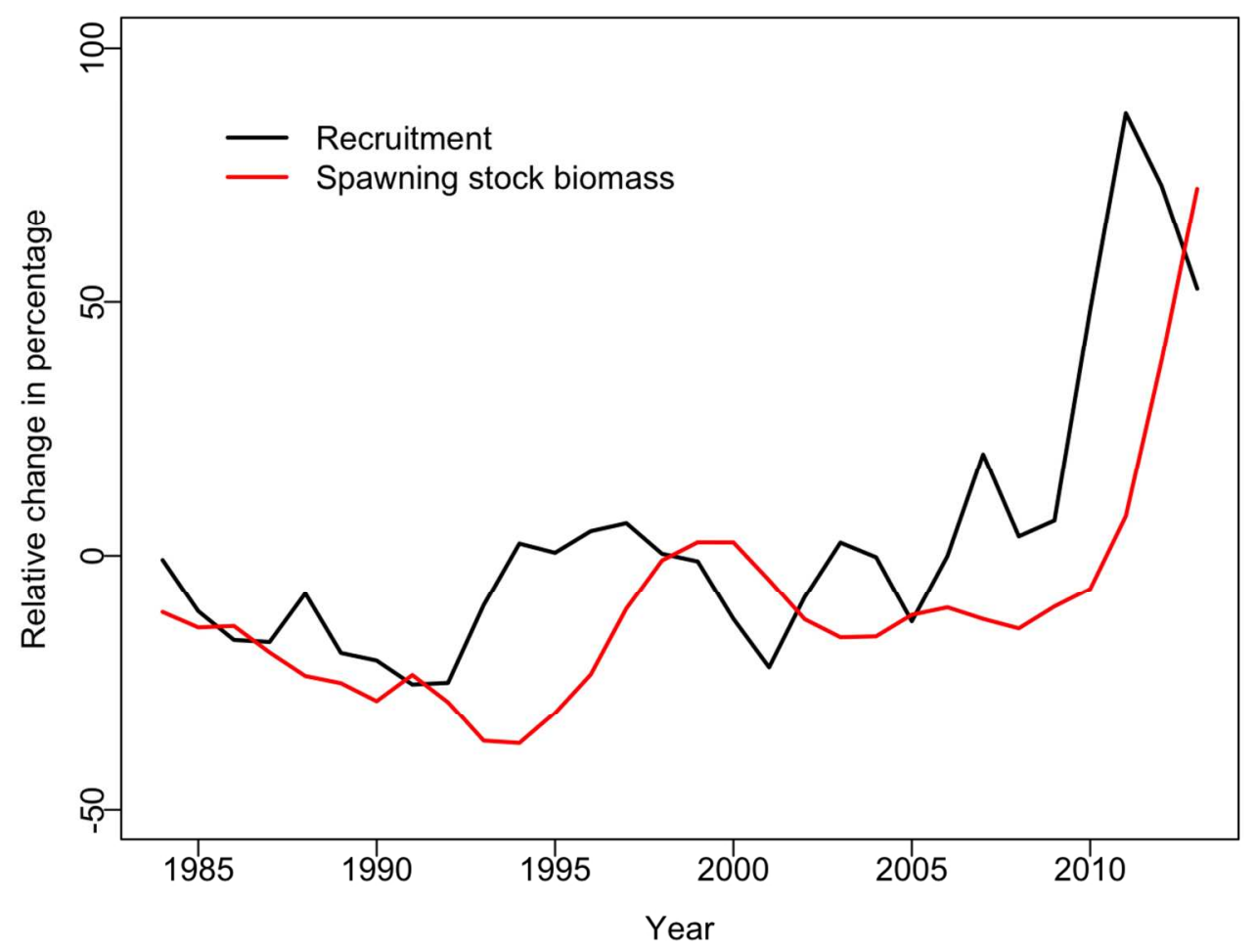

Figure 7. Relative changes in percentage for estimated recruitment and spawning stock biomass based on spatio-temporal and design-based indices. Note that the reference value is the estimates based on designbased index (for values greater than the reference value, the relative change in percentage should be a positive number).

$458 \times 352 \mathrm{~mm}(72 \times 72 \mathrm{DPI})$ 

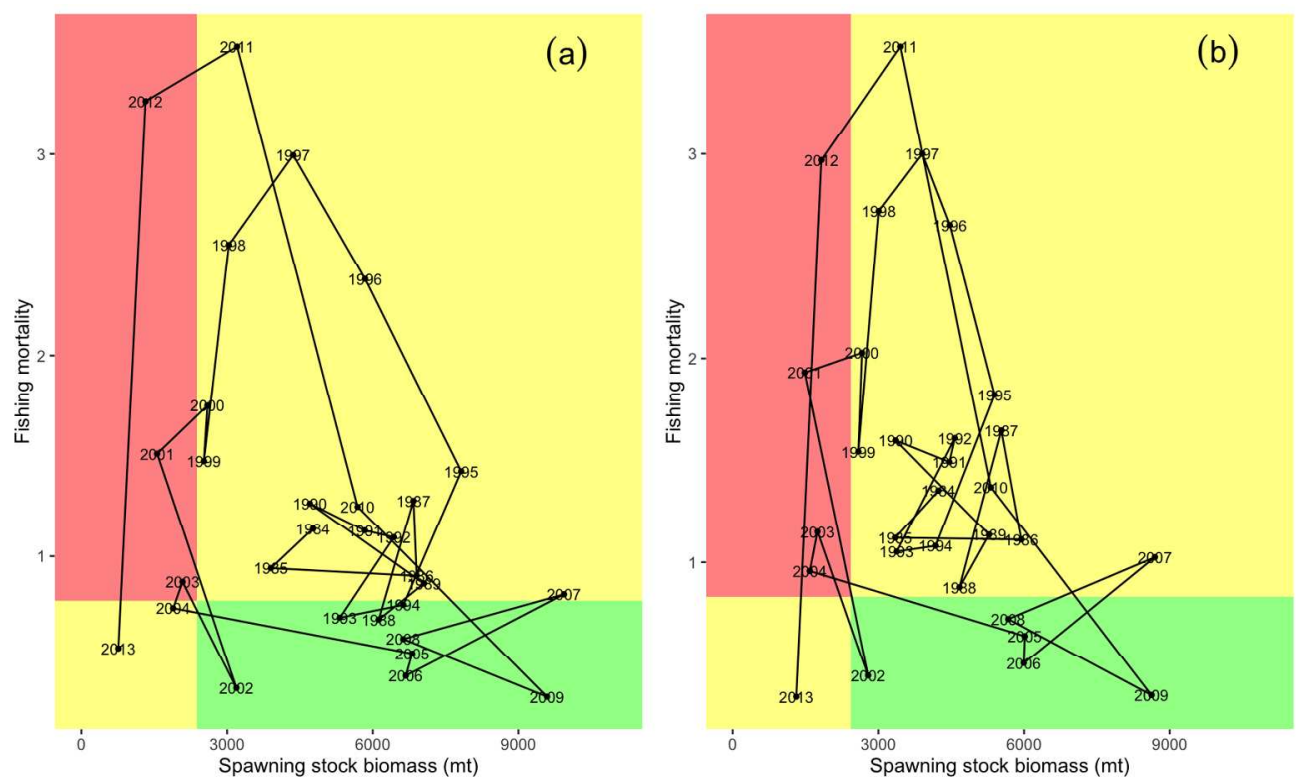

Figure 8. Status of northern shrimp stock in the Gulf of Maine determined based on stock assessment with (a) design-based index and (b) spatio-temporal index. The horizontal line (red and yellow) represents F40\% (the fishing mortality at which spawning stock biomass per recruit is $40 \%$ of virgin level) and the area above the line indicates that overfishing is occurring. The vertical line represents spawning stock biomass at $40 \%$ of virgin spawning stock biomass and the area to the left indicates that the stock has been overfished.

$705 \times 423 \mathrm{~mm}(72 \times 72$ DPI $)$ 


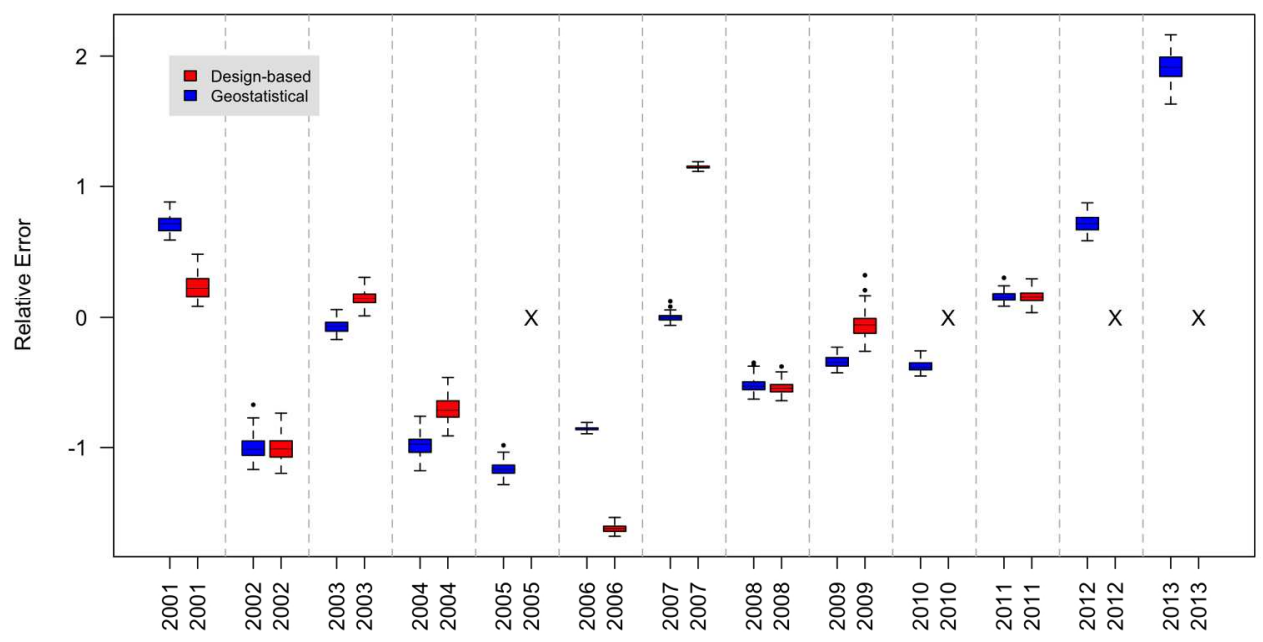

Figure 9. Relative error of one-year-ahead forecast index based on assessment model using design-based and spatio-temporal indices. Note that the assessment model using design-based index fails to forecast the abundance index for years 2005, 2010, 2012 and 2013 because of non-convergence.

$705 \times 423 \mathrm{~mm}(72 \times 72 \mathrm{DPI})$ 